\title{
Tradução, padrões e nuances: \\ um estudo de Linguística de Corpus \\ sobre diferentes prosódias semânticas \\ na língua fonte e na língua alvo ${ }^{1}$
}

\section{Translation, patterns and nuance: a study based on Corpus Linguistics about different semantic prosodies found in the source and target languages}

Maria Cecília Lopes*

FIP/UNIBERO - Anhanguera

Anhanguera - São Paulo / Brasil

\begin{abstract}
RESUMO: Neste artigo propomos uma discussão sobre a importância da prosódia semântica em traduções. Para tanto, estudamos sete itens lexicais analisados anteriormente por Coterril (2001), em inglês, que também ocorreram nos 162 textos jornalísticos do corpus paralelo desta pesquisa, formado por dados originalmente escritos em inglês (língua fonte) e traduzidos para o português (língua-alvo). As ferramentas Alinhador, Concordanciador Paralelo (CEPRIL, LAEL, PUC-SP) e WordSmith Tools 4 (SCOTT, 2004) foram usadas para a organização e o processamento dos dados. Como corpus de referência usou-se o Corpus do Português (DAVIES; FERREIRA, 2008). A análise mostrou resultados diferentes entre as prosódias semânticas de itens usados na língua fonte e na língua-alvo sugerindo que as escolhas tradutórias não imprimem o mesmo sentido do original. Concluimos este artigo sinalizando para a importância de estudos bilíngues que descrevam padróes lexicogramaticais, como a prosódia semântica, de maneira a contribuir para o estudo e a prática de tradução.
\end{abstract}

PALAVRAS-CHAVE: prosódia semântica; tradução; linguística de corpus

\footnotetext{
* cecilialopes@corpuslg.org

${ }^{1}$ Estudo piloto conduzido durante pesquisa de nível de doutoramento no Programa de Pós-Graduação em Linguística Aplicada e Estudos da Linguagem (LAEL/PUC$\mathrm{SP})$
} 


\begin{abstract}
This article aims to discuss the importance of semantic prosody in translation. Therefore, we present the analysis of seven lexical items previously studied in English by Coterril (2001) which also occurred in our parallel corpus (English-Portuguese) composed by 162 journalistic texts. The methodology included data submitted to Alinhador Paralelo, Concordanciador Paralelo (CEPRIL, LAEL, PUC-SP) and WordSmith Tools 4 (SCOTT, 2004). Corpus do Português (DAVIES; FERREIRA, 2008) was used as a reference corpus. The results showed different semantic prosody when comparing the itens used in the source and target languages (English-Portuguese). In our conclusion we offer some suggestions for future research considering two languages when investigating lexicogrammatical patterns such as the semantic prosody for Translation studies and practice.

KEYWORDS: semantic prosody; translation; corpus linguistics.
\end{abstract}

\title{
Introdução
}

A necessidade de conduzir esta pesquisa nasceu da nossa experiência como docente em cursos de especialização voltados para a área de tradução, pois pudemos observar que os alunos, ao se depararem com determinadas listas de palavras em dicionários bilíngues (inglês-português) como opçōes para suas traduçōes, questionavam qual daquelas possibilidades imprimiria o mesmo sentido dos textos originais. A ausência de informações sobre o uso das palavras por meio de exemplos da língua em uso que ilustrassem seu emprego impossibilitava uma escolha que fosse ao encontro do significado e do sentido das palavras em questão. Assim, essa lacuna encontrada na nossa prática docente serviu-nos como motivação para buscar em pesquisas em corpora caminhos que esclarecessem o sentido obtido a partir de determinadas escolhas tradutórias.

A pesquisa com corpora, apoiada nos pressupostos metodológicos e teóricos da Linguística de Corpus (doravante LC), tem se mostrado uma opção viável para auxiliar na escolha dos termos dicionarizados, pois com o auxílio de corpora é possível verificar a tipicidade do uso de uma determinada palavra, a influência das outras que a cercam, o contexto em que ocorre e qual o sentido que imprime. Portanto, apresentamos este artigo com o intuito de contribuir para os estudos na área de tradução, em especial aqueles voltados para a prática tradutória. O objetivo específico desta pesquisa está em descrever empiricamente, em corpora, um tipo específico de padronização lexical denominado prosódia semântica.

A justificativa para esta investigação partiu da necessidade de obter informaçōes não apenas acerca do significado de algumas palavras, mas o que elas sinalizam do ponto de vista do sentido (positivo, negativo ou neutro) quando coocorrem com outras na língua em uso, formando padróes lexicais. 
Ou seja, palavras em conjunto com outras produzem diferentes nuances que indicam sensações favoráveis, desfavoráveis ou neutras. Assim, a importância de estudos dessa natureza à luz da LC reside na possibilidade de contribuir para a melhoria da prática tradutória, desenvolvida por alunos de tradução e tradutores, pois permite que a escolha por determinado item lexical mantenha ou se aproxime do sentido pretendido no texto original.

Para tanto, trazemos a análise de alguns itens lexicais e seus padrões de prosódia semântica com o apoio de um corpus de referência monolíngue da língua portuguesa, o Corpus do Português (DAVIES; FERREIRA, 2008), doravante $\mathrm{CP}$, e outro de estudo composto por textos originais em inglês e suas traduções em português de tipologia paralela com originais e traduções dispostos lado a lado. Dada a natureza dos textos escolhidos, as traduções para o português apresentam a imagem que alguns jornais estrangeiros têm do Brasil. O leitor tem acesso a esses textos traduzidos por meio do sítio $U O L$ Midia Global, que apresenta seu serviço da seguinte forma:

[...] Em UOL Mídia Global o internauta pode ler diariamente textos de alguns dos mais importantes jornais dos EUA, como o "The New York Times", "USA Today", "Boston Globe", "Los Angeles Daily News", além dos europeus "Financial Times" (Inglaterra), "Le Monde" (França) e "El País" (Espanha), entre outros. [...] As reportagens sobre o Brasil recebem atenção especial no UOL Mídia Global. Tudo para que os internautas conheçam a visão estrangeira sobre as questōes nacionais, além de saber o que os formadores de opinião da Europa e Estados Unidos estão lendo sobre nosso país. ${ }^{2}$ (Meu grifo)

Essa explicação mostra de maneira inequívoca que os textos publicados são traduzidos de forma a apresentar aos leitores informações que ilustrem a forma como alguns veículos estrangeiros de comunicação entendem e retratam o Brasil. Uma questão relevante, porém, é a finalidade desse texto, uma vez que, para alguns, ele pode parecer um texto "frio", ou mesmo "requentado", já que a notícia veiculada gira em torno de assuntos já reportados diretamente pela mídia brasileira. Entretanto, pudemos constatar que esses textos servem como um meio para promover discussões acerca da imagem do Brasil na mídia estrangeira, por exemplo, o texto de 7 de novembro de 2008 do Financial Times traduzido para "Onda de fusōes de bancos deve ter início no

\footnotetext{
${ }^{2}$ Disponível em <http://sobre.uol.com.br/ultnot/novidade/noticias/ult98u231.jhtm>. Acesso em: 3 jul. 2007.
} 
Brasil", ${ }^{3}$ veiculado pelo UOL Midia Global e utilizado em uma estação de rádio brasileira em rede nacional para uma entrevista ao vivo. ${ }^{4}$ Dessa forma, a tradução, cujo assunto fora gerado no Brasil, escrito originalmente em inglês com o título "Wave of mergers set to break in Brazil", 5 repercutiu na mídia brasileira, tornando-se fonte geradora de debates. A questão que trazemos nesta pesquisa é se textos traduzidos como o exemplo acima refletem ou não as nuances produzidas pelos sentidos de alguns itens dos textos originais.

Na próxima seção deste artigo, trazemos a definição para o conceito da prosódia semântica, ilustrado com estudos que descrevem esse tipo de padrão lexicogramatical em uma ou duas línguas. Em seguida, apresentamos a metodologia usada, os corpora de estudo e de referência e um breve relato das ferramentas computacionais usadas no processamento dos dados. Finalizamos com a análise de dados, discussão e conclusões.

Do ponto de vista dos dados, as análises estão centradas em questôes relacionadas à prosódia semântica em português das seguintes palavras encontradas no corpus paralelo de estudo Brasilis: 6 encontrar, controlar, ciclo de, incidente, disputa discussão e conversa. A escolha destes itens deve-se pela presença de dados que descrevem a prosódia semântica de seus equivalentes na língua inglesa: encounter, control, cycle of, incident, dispute, discussion e conversation (COTERRIL, 2001). Como os sete itens em inglês ocorrem no corpus paralelo de estudo Brasilis, vislumbramos a possibilidade de verificar se a prosódia do inglês se mantém nas escolhas feitas nas traduções para a língua portuguesa.

\section{Prosódia Semântica: definições, aplicações e estudos}

Nesta seção trazemos as definições para o conceito da prosódia semântica ilustradas por algumas pesquisas e seus resultados em uma ou duas línguas (estudos comparativos).

Partington (1998) esclarece que o termo prosódia foi aplicado originalmente em estudos apresentados por Firth (1957), quando da análise

\footnotetext{
${ }^{3}$ Disponível em: <http://noticias.uol.com.br/midiaglobal/fintimes/>. Acesso em: 7 nov. 2008.

${ }^{4}$ Disponível em: <http://cbn.globoradio.globo.com/cbn/dinamico>. Acesso em: 7 nov. 2008.

${ }^{5}$ Disponível em: <http://www.ft.com/home/us>. Acesso em: 9 nov. 2008.

${ }^{6}$ Brasilis é o nome dado ao corpus de estudo paralelo composto por textos jornalísticos sobre o Brasil, publicados originalmente em inglês e traduzidos em português.
} 
de aspectos fonológicos que poderiam revelar uma coloração fonológica capaz de transcender os limites segmentais. De acordo com Partington, o conceito da prosódia semântica foi usado de forma até então inédita por Sinclair (1991), que passou a denominar desse modo o fenômeno linguístico indicativo do sentido agradável ou desagradável que certos padrões colocacionais produziam. Ao estudar o padrão formado por set in e palavras colocadas ao seu redor, Sinclair concluiu que normalmente há a indicação de eventos desagradáveis, já que set in habitualmente coloca-se com rot, despair, disillusion e prejudice, por exemplo.

A prosódia semântica é entendida por Partington (1998) como "a difusão de um colorido conotacional além das fronteiras de uma única palavra" ${ }^{7}$ De acordo com o autor, a conotação não se encontra apenas em um item, e sim em sua associação com os demais encontrados ao seu redor (colocaçôes). Ao estudar a palavra commit, ${ }^{8}$ o autor demonstra que o sentido desfavorável não é perceptível apenas ao examinar-se a palavra commit, mas interpretando-se os padrões lexicais formados por ela com as demais que se colocam ao seu redor.

Já para Louw (1993, p.157) trata-se de um processo no qual um item lexical está "imbuído de uma aura consistente de significado graças a presença de seus colocados $9 " .{ }^{10}$ Em sua pesquisa, o autor mostra a presença de colocados ao redor de determinados itens lexicais que formam uma prosódia semântica desfavorável, como no caso de utterly, que se coloca com burned, confusing e ridiculous. $\mathrm{O}$ autor destaca que o uso de determinadas palavras em certos contextos pode ser propositalmente contrário ao esperado. Portanto, a quebra da prosódia semântica serviria para produzir um tom irônico ao texto. Assim, compreendemos a prosódia semântica como o efeito de que se espalha, devido ao encontro de uma dada palavra com outras que coocorrem antes ou depois dela. A conotação indicada por uma determinada prosódia semântica não se apresenta apenas por um item lexical, mas por aquele item em associação com os demais que o cercam.

A próxima pesquisa em língua inglesa que destacamos é a de Stubbs (1995), que apresenta uma análise sobre o lema (palavra sem variações

\footnotetext{
7 Todas as traduções constantes desta tese foram feitas pela própria pesquisadora.

${ }^{8}$ A concordância é entendida aqui como uma lista processada por um programa computacional que apresenta a palavra de busca (item de estudo) ao centro (nódulo) acompanhada pelas demais palavras em seu entorno (colocados), conforme ocorrem em um determinado texto.

9 "the spreading of connotational colouring beyond single word boundaries".

10 "A consistent aura of meaning with which a form is imbued by its collocates [...]".
} 
flexionais) cause e seus colocados, partindo das seguintes premissas: as palavras apresentam perfis semânticos ou prosódias distintas; a força de associação entre palavras pode ser mensurada quantitativamente. Em sua pesquisa, o autor buscou cause num corpus de cerca de 1 milhão de palavras (LOB corpus) e concluiu que cerca de $80 \%$ das ocorrências eram acompanhadas de colocados com perfil semântico negativo.

Para Hunston (1995, apud HUNSTON; FRANCIS, 2000, p.104) "uma palavra pode apresentar uma determinada prosódia semântica se tipicamente coocorrer com outras palavras formando um conjunto semântico específico." ${ }^{11}$ Portanto, não basta estudar o significado de um item isolado mas também o sentido realizado por ele em conjunto com seus colocados (palavras nas cercanias de outras) e a associação que se estabelece a partir do conjunto semântico formado.

A coocorrência típica das palavras não é um dado encontrado com frequência nas obras de referência tradicionais de trabalhos de tradução, como dicionários e glossários bilíngues. Normalmente, esses recursos apresentam listas de traduçóes diretas sem apontar para a tipicalidade da ocorrência de certa palavra com outra e sem mencionar o sentido produzido por esses encontros na língua em uso. Assim, ao pinçar de uma dessas obras uma determinada palavra, colocando-a ao lado de outras tantas, é possível produzir-se padrões atípicos que podem causar estranheza na tradução e ainda afastar-se o sentido do texto original. De acordo com Berber Sardinha (2004)

A prosódia semântica, assim como a colocação, cria uma relação de expectativa para com o ouvinte ou leitor. $\mathrm{Na}$ tradução, a quebra de padrōes entre uma língua e outra pode trazer implicaçôes relacionadas à fidedignidade, aceitabilidade e legibilidade do texto traduzido ou vertido. A quebra da prosódia semântica, por sua vez, implica na mudança da conotação intencionada pelo falante ou escritor. (BERBER SARDINHA, 2004, p.238)

A prosódia semântica foi escolhida neste estudo pela possibilidade de descrever padrōes linguísticos típicos e os sentidos que imprimem, bem como pela relevância que este tipo de informação tem nos estudos e na prática de tradução. Partington compreende que a prosódia semântica

11 " [...] a word may be said to have a particular semantic prosody if it can be shown to co-occur typically with other words that belong to a particular semantic set." 
é uma área importante de pesquisa para os estudos de tradução.[...] palavras cognatas e semelhantes em duas línguas que se relacionam podem possuir prosódias semânticas bem diferentes. ${ }^{12}$ (PARTINGTON, 1998, p.77)

Para Kenny (2001, p.100), a prosódia semântica, do ponto de vista pragmático, revela a atitude do usuário da língua ao escolher certos grupos lexicais que regularmente ocorrem na língua acompanhados por seus colocados. A autora relata que certos perfis esperados para a prosódia semântica podem ser o início para estudos de tradução que envolvam a normalização (proximidade com a LA). Em havendo ocorrências na LF com um padrão colocacional inesperado ou criativo (clash), traduzidas para a LA com um padrão esperado, haveria evidências de que a opção é pelo mais convencional ou normalizado na LA.

Em um estudo comparativo, Partington (1998) contrasta os padrões colocacionais entre palavras aparentemente cognatas em duas línguas: impressive (inglês) e impressionante (italiano). Segundo o autor, impressive coloca-se com itens cuja prosódia é favorável ou positiva como achievement, best, talent. Já impressionante coloca-se tipicamente com itens desfavoráveis como price rises, assassination atempts (palavras traduzidas pelo autor do italiano para o inglês).

Em outra pesquisa cujos dados foram comparados entre duas línguas (inglês e português), Berber Sardinha (1999, p.10) analisou as prosódias de happen / acontecer e cause /causar, motivado pelos dados já analisados no inglês para happen e cause (STUBBS, 1995) O autor concluiu que a prosódia do primeiro par é oposta (happen: negativa; acontecer positiva ou neutra) e a do segundo par (cause/causar) é igualmente negativa em inglês e português.

Vale a pena mencionar, como destaca Berber Sardinha (2004), que estudos comparativos entre português e inglês podem beneficiar-se de dados já analisados em inglês. Isso corrobora a importância de investigações com dados paralelos, em especial para fins de tradução como propomos aqui.

Assim sendo, o estudo que colaborou com dados em inglês para a pesquisa que apresentamos em detalhes nas próximas seções é de Coterril (2001), que analisou um corpus de estudo com trechos do julgamento de $\mathrm{O}$. J. Simpson nos Estados Unidos. Esse caso é analisado em seu artigo, tendo

12 "Semantic prosody is an important area of research for translation studies. [...] cognate, or 'look-alike' words in two related languages can have very different semantic prosodies." 
como base as cem mil primeiras palavras das primeiras declarações de abertura ${ }^{13}$ da promotoria e da defesa.

A autora aborda a questão das escolhas linguísticas na área forense, mais precisamente a importância da prosódia semântica e o impacto provocado por essas escolhas na condução de um julgamento, que podem culminar em um veredicto favorável ou não ao acusado. Como o corpus de referência usado em sua pesquisa é um corpus de inglês geral (Bank of English), os resultados apontados pela autora também interessam à descrição da língua inglesa geral e, consequentemente, aos textos na LF do corpus Brasilis.

A partir de seu corpus de estudo, a autora analisa a prosódias de: encounter, control, cycle of (violence), incident(s), (domestic) dispute, discussion e conversation. Encounter foi o verbo utilizado pela promotoria ao se referir as vítimas que constavam no processo. De acordo com o corpus de referência Bank of English, ${ }^{14}$ encounter tem prosódia negativa. Outro item estudado foi control, que reforça a ideia de que o acusado controlava sua ex-esposa. $\mathrm{O}$ estudo dessa palavra não apenas indicou uma prosódia negativa como também algumas diferenças dependendo do gênero (masculino ou feminino) daquele que realiza a ação. Constatou-se que as mulheres controlam suas emoções e os homens controlam sua raiva.

Em seguida, passou-se à análise de cycle of, extraído de cycle of violence, usado diversas vezes pela promotoria para relatar o tipo de relação que o casal mantinha. Cycle of apresentou uma colocação com circunstâncias ruins (problemas, conflitos) com prosódia semântica negativa. $\mathrm{O}$ agrupamento lexical cycle of violence foi encontrado no corpus de referência com uma predominância de colocados que revelam um caráter prolongado, como algo que tende a piorar com o passar do tempo.

A defesa, por sua vez, tentou desfazer a imagem do cycle of violence, usando incident. No corpus de referência, os colocados de incident(s) minimizam fatores negativos. Para a autora, a prosódia de incident tanto pode ser neutra, uma vez que há um caráter de eventualidade (isolated, first, sporadic), quanto negativa pela associação com palavras de caráter desfavorável (violent, unpleasant).

\footnotetext{
13 “opening statements"

${ }^{14}$ Cabe salientar que o Bank of English é um corpus que permite àqueles que o acessam uma visão geral da língua inglesa em diversas áreas.
} 
Outra forma para minimizar as agressões alegadas pela promotoria ocorrera quando a defensoria fez uso de palavras que transferiram a questão da violência para o âmbito verbal (dispute, discussion, conversation). O padrão domestic dispute, porém, pareceu ser inadequado, pois, ao pesquisar esse agrupamento no corpus de referência, a autora encontrou colocados que sugerem uma prosódia negativa (drunk, assault). Já discussion apresenta colocados relacionados a embates verbais (sem violência física), com prosódia positiva em contextos que remetem a conversas de caráter intelectual e profissional. No caso de conversation, a prosódia positiva é mais saliente e orienta o uso desse item lexical que aponta para o discurso socialmente aceito sem a conotação de violência ou ameaça aos participantes. Coterril (2001) finaliza sua pesquisa enfatizando a importância das primeiras declarações proferidas pela promotoria e pela defesa na construção da fundamentação que orienta a linha de trabalho de um caso jurídico.

Partimos, então, da análise acima dos itens lexicais estudados por Coterril em inglês (encounter, control, cycle of (violence), incident(s), (domestic) dispute, discussion e conversation) e os resultados encontrados para suas prosódias para comparar às traduções para o português do corpus paralelo de estudo Brasilis. Assim, temos por objetivo verificar se a prosódia semântica em inglês foi mantida nos textos traduzidos para o português.

\section{Metodologia: o tratamento dos dados}

O corpus paralelo de estudo, Brasilis, é composto por cento e sessenta e dois textos na língua inglesa (doravante LF) e suas traduções para a língua portuguesa (doravante LA). ${ }^{15}$ A TAB. 1 a seguir apresenta o detalhamento da sua composição em número de palavras totais (tokens) e de palavras distintas (types) em cada língua:

\footnotetext{
${ }^{15}$ Textos jornalísticos originais publicados entre 2004 e 2008 pelos jornais on-line The New York Times, Financial Times, USA Today e Herald Tribune, traduzidos e publicados pelo sítio brasileiro UOL Midia Global.
} 


\section{TABELA 1}

Composição do Corpus paralelo de estudo Brasilis

\begin{tabular}{lc}
\hline \multicolumn{2}{c}{ Brasilis inglês (original) } \\
\hline Palavras totais & 143.226 \\
Itens & 13.143 \\
\hline \multicolumn{2}{c}{ Brasilis português (tradução) } \\
\hline \multicolumn{2}{c}{ Palavras totais } \\
Itens & 143.123 \\
\hline
\end{tabular}

Todos os textos na LA foram extraídos do sítio UOL Mídia Global e dos jornais cujos textos foram originalmente escritos na LF. A formação do corpus paralelo contou com o auxílio do Alinhador Paralelo Online ${ }^{16}$ e do Concordanciador Paralelo Online ${ }^{17}$ (CEPRIL, LAEL, PUC-SP).

Para estudar as prosódias semânticas das sete palavras em português recorremos ao CP on-line (18 $^{1}$ DAVIES; FERREIRA, 2008) com cerca de quarenta e cinco milhões de palavras extraídas de textos de diferentes gêneros. No sítio desse corpus de referência, selecionamos a seção de português brasileiro e buscamos uma a uma as palavras objeto desta pesquisa. O resultado apresenta o total de ocorrências e a palavra de busca em contexto a partir de linhas de concordâncias. ${ }^{19}$ Por exemplo:

, uma filósofa. Por isso, é difícil você encontrar uma grande pensadora. A não como essa. Houve também a dificuldade de encontrar cantores líricos no Recife nal, por isso gosto deles. Desejei muito encontrar nos retalhos de que venho

Foram analisados, com base nas linhas de concordância fornecidas pelo sítio do CP, os cem primeiros colocados (total de ocorrências somadas todas as posições no horizonte $5 \mathrm{R} \mathrm{e} 5 \mathrm{~L}$, ou janela 5:5) de palavras de conteúdo com ocorrência maior igual a dois $(\geq 2)$ para determinar um possível padrão e a prosódia mais típica da palavra de busca. O sítio fornece uma lista de colocados

\footnotetext{
${ }^{16}$ Disponível em: <http://lael.pucsp.br/corpora/alinhador>. Acesso em: 5 maio 2008.

${ }^{17}$ Disponível em: <http://www.corpuslg.org/tools/parallelconc/>. Acesso em: 7 jul. 2009.

${ }^{18}$ Disponível em <http://www.corpusdoportugues.org/>. Acesso em: 3 maio 2008.

${ }^{19}$ Concordância é entendida aqui como uma lista processada por um programa computacional que apresenta a palavra de busca (item de estudo) ao centro (nódulo), acompanhada pelas demais palavras em seu entorno (colocados), conforme ocorrem em um determinado texto.
} 
calculados a partir do cálculo estatístico da Informação Mútua. Esse cálculo possibilita o acesso a colocados não tão frequentes na língua, mas de ocorrência constante.

Como o sítio apresenta até 50 resultados (linhas de concordância) para termos acesso e uma visão geral das ocorrências das palavras de estudo, decidimos coletar as concordâncias, copiá-las, colá-las, salvá-las em arquivos de extensão .txt. e processá-las pela ferramenta Concord do programa WordSmith Tools 4 (SCOTT, 2004). Por exemplo, um dos itens de estudo, encontrar, ocorreu 1.186 vezes no BP, mas os resultados eram apresentados na janela em grupos de até 50. Já pela ferramenta Concord foi possível visualizar todas as linhas, como exemplificamos na Tela 1 abaixo:

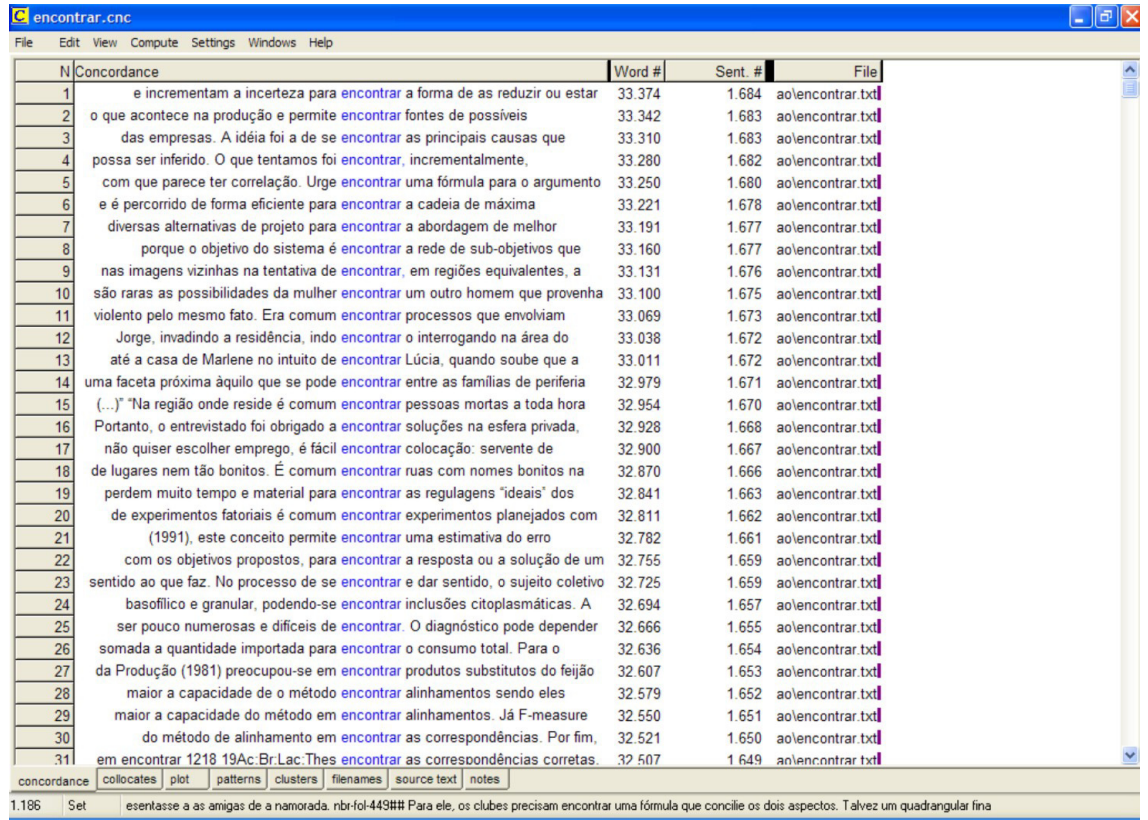

Tela 1: lista de concordâncias para encontrar

A lista de concordâncias obtidas a partir do Concordancer possui diversas informações em suas colunas como: $N$ (número em sequência da linha de concordância), Concordance (a linha de concordância com o nódulo centralizado), Word \# (posição da palavra no texto), Filename (nome do arquivo), entre outras. A segunda aba, na parte inferior da ferramenta, dá acesso direto aos colocados da palavra de busca (nódulo). A Tela 2 a seguir exemplifica a lista de colocados para encontrar: 


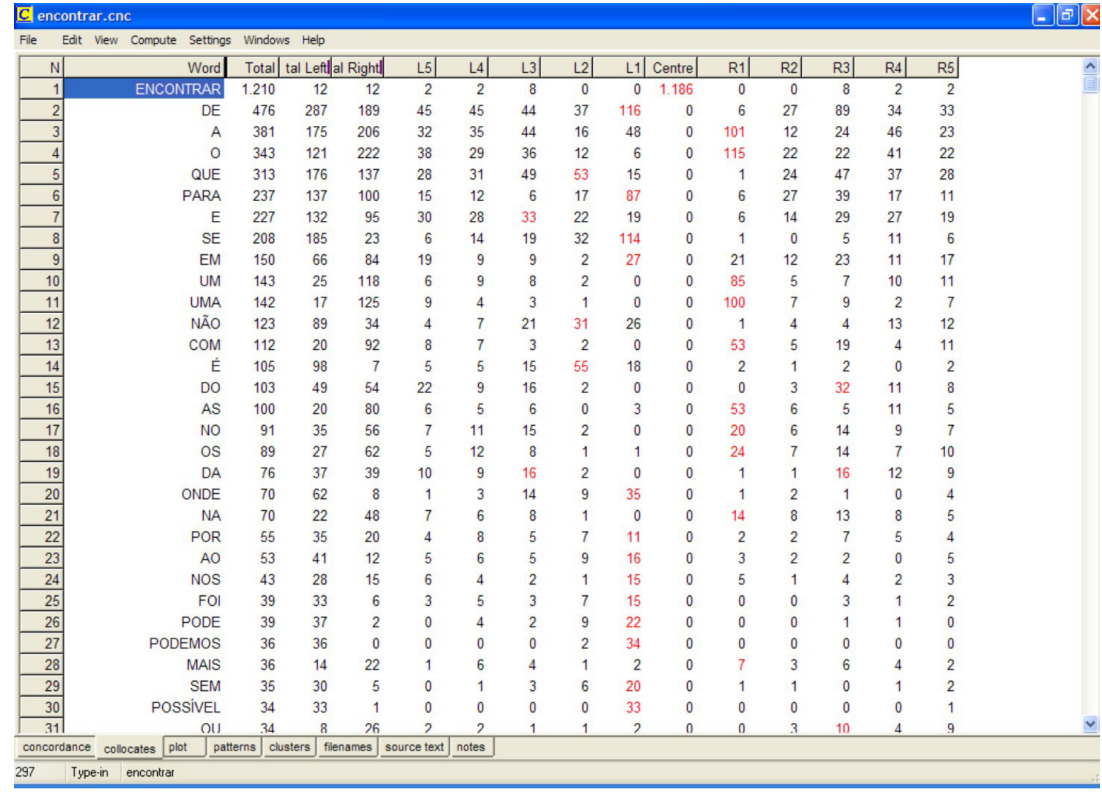

Tela 2: lista de colocados para encontrar

As colunas da lista de colocados acima são: $N$ (número em sequência do colocado), Word (o colocado, Total (o número de vezes que o colocado ocorre), Total Left (total de vezes que se coloca à esquerda), Total Right (total de vezes que se coloca à direita), $L 5$ a $L 1$ (número total de vezes em que o colocado ocorreu nas posiçōes referentes a cinco, quatro, três, duas e uma palavra à esquerda do nódulo), Centre (total de ocorrências do colocado como nódulo), $R 5$ a $R 1$ (número total de vezes em que o colocado ocorreu nas posições referentes a cinco, quatro, três, duas e uma palavra à direita do nódulo). Em relação ao horizonte dos colocados, Berber Sardinha (2009) esclarece que

[...] o mais comum é estabelecer um horizonte de cinco palavras para cada lado do termo de busca, portanto $5 L$ e $5 R$. Isso garante que a maioria das palavras de interesse para descrição dos padrōes do termo de busca serão computadas quando do acionamento da tabela de colocados. De posse da tabela de colocados, o usuário poderá, então, fazer a seleção dos colocados que lhe interessa na própria tabela, podendo se concentrar nos colocados mais relevantes para seu propósito (BERBER SARDINHA, 2009, p. 94).

De posse da lista dos cem primeiros colocados com frequência total mínima de dois entre as posições de $5 \mathrm{R}$ e $5 \mathrm{~L}$ do nódulo, iniciamos a análise 
dos padrões lexicogramaticais que indicassem a prosódia semântica em português. Em seguida, cada uma das palavras na LF (COTERRIL, 2001) foi comparada à prosódia encontrada na LA (corpus paralelo de estudo Brasilis) para verificar se as prosódias da LF foram mantidas ou não na LA, como apresentamos na próxima seção dedicada à análise.

\section{Análise: as cores e nuances das sete palavras na língua portuguesa}

Com base no estudo do Bank of English conduzido por Coterril (2001), apresentamos na TAB. 2 abaixo os itens em inglês na primeira coluna e, na segunda, a prosódia semântica apresentada pela autora. A terceira coluna traz as traduções desses itens como encontrados em português no corpus paralelo de estudo Brasilis:

TABELA 2

Itens pesquisados em inglês (COTERRIL, 2001) e em português (corpus paralelo de estudo Brasilis)

\begin{tabular}{l|c|c}
\hline $\begin{array}{l}\text { 1. Item lexical em inglês } \\
\text { (COTERRIL, 2001) }\end{array}$ & $\begin{array}{c}\text { 2. Prosódia semântica } \\
\text { (COTERRIL, 2001) }\end{array}$ & $\begin{array}{l}\text { 3.Tradução do item lexical no } \\
\text { corpus paralelo de estudo Brasilis }\end{array}$ \\
\hline 1. (to) encounter & negativa & encontrar \\
2. to control & negativa & controlar \\
3. cycle of & negativa & ciclo de(o/a) \\
4. incident(s) & neutra, negativa & incidente(s) \\
5. dispute & negativa & disputa \\
6. discussion & positiva & discussão \\
7. conversation & positiva & conversa \\
\hline
\end{tabular}

Como corpus de referência para o português, utilizamos o CP que disponibiliza quarenta e cinco milhões de palavras escritas em português de Portugal e do Brasil desde o século 13, cujas fontes incluem textos da língua falada, escrita, de ficção, acadêmicos e jornalísticos. Nesse sítio, é possível usar alguns filtros, dependendo do objetivo da pesquisa. Algumas das opçôes são: português do Brasil, português de Portugal e períodos de tempo (entre séculos 14 e 20). Para este estudo, selecionamos português do Brasil, século 20 e qualquer tipo de fonte.

O primeiro item investigado, encontrar, apresentou 1.248 ocorrências e, com base nas linhas de concordância fornecidas pelo sítio do CP, analisamos os cem primeiros colocados (total de ocorrências somadas todas as posições no horizonte 5R e 5L) de palavras de conteúdo com ocorrência maior ou igual a 
dois $(\geq 2)$ para determinar um possível padrão e a prosódia mais típica da palavra de busca. Entre esses colocados, foram localizados alguns que dão a esse item uma prosódia semântica negativa: difícil (29), resistência (21), dificuldades (12), dificuldade (8), problemas (7), dificeis (7), irregularidades (5), problema (4). Para prosódia positiva: solução (26), fácil (10), sorte (9), soluções (6), esperança (5), desenvolvimento (5), oportunidade (4). Na TAB. 3 temos o total encontrado para cada prosódia e sua respectiva porcentagem em relação ao total de ocorrências dos colocados estudados:

TABELA 3

Tipos de prosódia e suas frequências para encontrar

\begin{tabular}{l|c|c}
\hline \multicolumn{1}{c|}{ Prosódia } & $\begin{array}{c}\text { Total de ocorrências } \\
\text { dos colocados estudados }\end{array}$ & Frequência em $\%^{20}$ \\
\hline Negativa & 93 & $59 \%$ \\
Positiva & 65 & $41 \%$ \\
TOTAL & 158 & \\
\hline
\end{tabular}

Conclui-se que encontrar possui uma prosódia negativa na língua portuguesa. No corpus paralelo de estudo Brasilis uma das ocorrências paralelas foi:

\begin{tabular}{|c|c|}
\hline $\begin{array}{l}\text { Almost a hundred years before, Theodore } \\
\text { Roosevelt came to the Amazon with his own } \\
\text { series of setbacks (he had just lost the } 1912 \\
\text { election, among other things) only to } \\
\text { encounter more disasters on a harrowing } \\
\text { near-death expedition down an unexplored } \\
\text { tributary called the Rio da Dúvida, or } \\
\text { River of Doubt. }\end{array}$ & $\begin{array}{l}\text { Há quase cem anos, Theodore } \\
\text { Roosevelt foi para a Amazônia com } \\
\text { seus vários problemas (ele havia } \\
\text { perdido as eleiçóes de 1912, entre } \\
\text { outras coisas) apenas para encontrar } \\
\text { mais desastres numa expedição } \\
\text { martirizante e quase fatal pelo } \\
\text { inexplorado Rio da Dúvida. }\end{array}$ \\
\hline
\end{tabular}

Nesse exemplo, encontrar se coloca com mais desastres e, assim, segue a tendência de uma prosódia negativa, ou seja, aquilo que o falante brasileiro de língua portuguesa espera encontrar na maioria das vezes ao redor de encontrar são palavras que remetem a ideias negativas e desfavoráveis. Metaforicamente, pode-se dizer que encontrar atrai uma nuvem escura de significados.

A segunda palavra pesquisada, controlar, ocorreu 253 vezes no CP. Não há colocados que deem a esse item um caráter favorável ou uma prosódia

${ }^{20}$ Cada prosódia apresentou um determinado número de ocorrências que foram divididas pelo total para obtenção da frequência por prosódia disposta na $3^{\text {a }}$. coluna. 
positiva. Há a presença de colocados que remetem, talvez, à prosódia neutra: órgãos(6), fluxo(5), tudo(4), alguns(3), custo(3), processos(3).

Um caso interessante que divide o uso em duas prosódias, dependendo da posição do colocado e sua função é informaçōes. Em duas ocorrências colocase antes de controlar. Ou seja, as informaçôes são usadas para controlar algo. Nas outras três, as informações são controladas e isso pode indicar uma prosódia negativa com o sentido de censura.

A presença de verbos que se colocam no horizonte de $5 \mathrm{~L}$ e $5 \mathrm{R}$ dão a controlar um caráter mais incisivo: fiscalizar (3), monitorar (3), planejar (3) e coordenar (2). Além disso, quem controla normalmente é um órgão do governo (Polícia, presidente, vice-presidente, primeiro-ministro), um partido (PMDB, PTB) ou uma entidade de prestígio (ONU, Banco Mundial, G-7, Igreja), além de substantivos comuns que remetem a um participante com poder sobre aquilo / aquele que controla (empresa, órgão civil/militar).

Há 51 colocados que formam um padrão lexicogramatical de prosódia negativa. Os que atribuem algo como impossivel (6), difícil (4) de controlar. Algumas sensaçóes que se quer controlar como: ansiedade (3), excesso (3), perturbadores (2), medo (3); problemas médicos que se deseja controlar: hipertensão (3), contaminação (2), hipertensão (2), drogas (2). Problemas econômicos: inflação (5), custos (3), despesas (3), consumo (4), economia (3). O total de ocorrências e as prosódias estão na TAB. 4 abaixo:

TABELA 4

Tipos de prosódia e suas frequências para controlar

\begin{tabular}{l|c|c}
\hline Prosódia & $\begin{array}{c}\text { Total de ocorrências } \\
\text { dos colocados estudados }\end{array}$ & Frequência em \% \\
\hline Neutra & 19 & $26 \%$ \\
Negativa & 54 & $74 \%$ \\
TOTAL & 73 & \\
\hline
\end{tabular}

A partir do corpus paralelo de estudo Brasilis extraímos o seguinte exemplo em paralelo para control/ controlar:

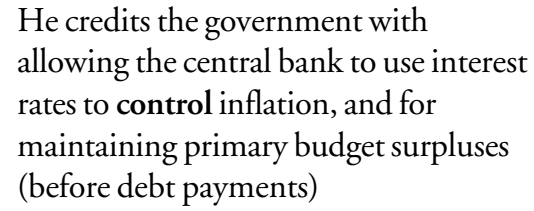

He credits the government with allowing the central bank to use interest rates to control inflation, and for maintaining primary budget surpluses (before debt payments)

Ele credita isso ao governo por este permitir que o Banco Central use as taxas de juros para controlar a inflação e por manter superávits orçamentários primários (antes dos pagamentos da dívida) 
A escolha por controlar na tradução colocado junto a inflação indica a tendência da prosódia negativa na língua portuguesa.

A terceira palavra pesquisada ciclo, seguido da preposição de, apresentou 149 ocorrências no CP. Para prosódia negativa alguns dos colocados são: voracidade (11), carestia (11), morte (3), subdesenvolvimento (2), patético (2). Exemplos de prosódia positiva podem ser extraídos com os seguintes colocados: prosperidade (12), desenvolvimento (4), crescimento (3). Há, também, a presença de colocados que indicam uma prosódia neutra com os seguintes padróes lexicogramaticais: ciclo de + evento: palestras (6), conferências (3); ciclo de + substantivos relacionados às ciências econômica, biológica e bioquimica: vida (27), Kondratieff(13), celular(7), ácidos(6), tricarboxílicos(6), nitrogênio(5) Krebs (3), secagem (3), moldagem (3), carbono(2). Curiosamente, ciclo de violência (tradução para cycle of violence citado no estudado de Coterril, 2001) ocorreu apenas uma vez no BP. Na Tabela 5 abaixo apresentamos a frequência para cada tipo de prosódia:

TABELA 5

Tipos de prosódia e suas frequências para ciclo

\begin{tabular}{l|c|c}
\hline Prosódia & $\begin{array}{c}\text { Total de ocorrências } \\
\text { dos colocados estudados }\end{array}$ & Frequência em \% \\
\hline Neutra & 85 & $64 \%$ \\
Negativa & 29 & $22 \%$ \\
Positiva & 19 & $14 \%$ \\
TOTAL & 133 & \\
\hline
\end{tabular}

A prosódia semântica neutra está tipicamente associada a ciclo de a partir do corpus de referência CP. No corpus paralelo de estudo Brasilis não foi localizado o par cycle oflciclo de, mas sim o par cycle of/ciclo (adjetivo) de:

Nepstad is one of numerous researchers who say a vicious cycle of drought and the fires it triggers could speed the transformation of one-third of the Amazon into scrub vegetation in the Nepstad é um dos vários pesquisadores que dizem que um ciclo vicioso de seca e incêndios pode apressar a transformação de um terço do Amazônia em arbustos the coming decades. nas próximas décadas. 
O quarto item estudado, incidente, é um tanto curioso, já que esse item lexical pode, por si só, remeter a um sentido negativo ou desfavorável. Segundo o dicionário Houaiss online, ${ }^{21}$ incidente possui várias acepçôes, entre elas:

2. evento, fato que sobrevém no transcurso de um acontecimento principal 2.1 acontecimento imprevisível que modifica o desenrolar esperado e normal de uma ação e provoca uma interrupção sentida ger. como inconveniente 2.2 dificuldade passageira que não modifica o desenrolar de uma operação, de uma linha de conduta

A imprevisibilidade e a dificuldade passageira de um evento, que o torna um incidente, foi estudada em conjunto com os colocados encontrados junto com as cento e noventa e duas ${ }^{22}$ ocorrências de incidente. Há poucos colocados que minimizam seu caráter negativo, como por exemplo: pequeno (3), mínimo (2), trivial (2). Para a prosódia negativa: grave (10), comprometer (6), sobressalto (6), receando (6), derrota (5), desastroso (5), desagradável (5), guerra (5), lamentável (4). Portanto, concluímos que os colocados mais recorrentes reforçam a prosódia desfavorável:

TABELA 6

Tipos de prosódia e suas frequências para incidente

\begin{tabular}{l|c|c}
\hline Prosódia & $\begin{array}{c}\text { Total de ocorrências } \\
\text { dos colocados estudados }\end{array}$ & Frequência em \% \\
\hline Negativa & 52 & $88 \%$ \\
Positiva & 07 & $12 \%$ \\
TOTAL & 59 & \\
\hline
\end{tabular}

No corpus paralelo de estudo Brasilis duas das três ocorrências de incidente apresentam um perfil semântico negativo. Por exemplo:

\footnotetext{
${ }^{21}$ Disponível em: <http://houaiss.uol.com.br/busca.jhtm?verbete=incidente\&x= $0 \& y=0 \&$ stype $=\mathrm{k}>$. Acesso em: 10 jun. 2008.

${ }^{22}$ Cinquenta dessas ocorrências formam o padrão radiação incidente, cujo sentido não se refere a um acontecimento imprevisível e, portanto, não incluído na análise.
} 
They note that in 1992, when the

United Nations sponsored a global $\quad$ Elas lembram que em 1992, quando as Naçôes meeting on the environment in Rio, Unidas promoveram uma conferência global the event went off without incident sobre meio ambiente no Rio, o encontro despite predictions of a crime wave.

ocorreu sem incidentes, apesar das previsões de uma onda de criminalidade.

Para disputa, a quinta palavra investigada, foram encontradas 483 ocorrências. Alguns dos colocados das concordâncias formam uma prosódia negativa, tais como: acirrada (20), longa (5), grave (5), judicial (5). Observase a presença de alguns poucos colocados que, associados ao nódulo, resultam numa prosódia positiva não em número expressivo (liderança(7)). A maioria dos colocados estudados no CP dão a este item um perfil neutro, no sentido de tentar obter uma vaga ou estar envolvido em algum tipo de contenda: mundial (23), interna (14), eleiçôes (13), liderança (13), mandatos (13), poder (13), eleitoral (12), fronteiras (9). Na TAB. 7 apresento a frequência para cada tipo de prosódia:

TABELA 7

Tipos de prosódia e suas frequências para disputa

\begin{tabular}{l|c|c}
\hline Prosódia & $\begin{array}{c}\text { Total de ocorrências } \\
\text { dos colocados estudados }\end{array}$ & Frequência em \% \\
\hline Neutra & 110 & $72 \%$ \\
Negativa & 35 & $23 \%$ \\
Positiva & 07 & $5 \%$ \\
TOTAL & 152 & \\
\hline
\end{tabular}

Em três das onze ocorrências analisadas, dispute foi traduzida no corpus paralelo de estudo Brasilis como briga e polêmica. Por exemplo:

Additional environmental impact studies are under way, but the dispute now raging in Rondônia appears to have more to do with politics and economics than science and nature.
Estudos de impacto ambiental adicionais estão sendo desenvolvidos, mas a briga que agora é travada em Rondônia parece ser mais política e econômica do que de ciência e natureza. abaixo:

Nas demais oito, dispute foi traduzido por disputa, como no exemplo 
Brazil tries to ease Bolivian gas dispute By Hal Weitzman in Lima and agencies Published: September 21
22/09/2006 Presidente do Brasil se oferece para negociar em tentativa de abrandar disputa sobre o gás boliviano Hal Weitzman em Lima

Se em inglês, de acordo com Coterril (2001), dispute tem prosódia negativa e em português, conforme a TAB. 7, disputa coloca-se a outros itens formando um perfil semântico neutro, então outras escolhas para dispute na LA poderiam traduzir com acuidade o sentido negativo da LF.

Para a sexta palavra estudada, discussão, foram encontradas 418 ocorrências no corpus de referência. Os achados no estudo de Coterril (2001) apresentaram colocados para a palavra discussion que atribuem a esse termo uma prosódia favorável relacionada a temas de caráter intelectual e profissional. Concluímos, com base nos achados do CP, que discussão coloca-se com palavras cujas características indicam a neutralidade para prosódia semântica: grupo (22), textos (19), listas (15), tópicos (7), grupos (6), comunidade (5). Para prosódia positiva apenas ganhar (9) e livre (6). E para a prosódia negativa aborto (5). A TAB. 8 abaixo sinaliza a porcentagem de cada prosódia em relaçáo aos colocados apresentados aqui:

TABELA 8

Tipos de prosódia e suas frequências para discussāo

\begin{tabular}{l|c|c}
\hline Prosódia & $\begin{array}{c}\text { Total de ocorrências } \\
\text { dos colocados estudados }\end{array}$ & Frequência em \% \\
\hline Neutra & 76 & $79 \%$ \\
Positiva & 15 & $16 \%$ \\
Negativa & 05 & $5 \%$ \\
TOTAL & 96 & \\
\hline
\end{tabular}

Cabe salientar que há itens que se colocam ao redor de discussão, cuja prosódia parece ser subjetiva e sua classificação pode depender dos objetivos do analista e de questôes ideológicas. É o caso de nomes de políticos e partidos encontrados no CP (Maluf(7), PFL(7) e PT(6)).

No corpus paralelo de estudo Brasilis, escolheu-se discussão como tradução para as seis ocorrências de discussion: 


\begin{tabular}{|l|l|}
\hline "We are experiencing an auspicious & "Nós estamos experimentando um \\
moment in Brazil right now," Mr. da & momento auspicioso no Brasil no \\
Silva, 61, said in his first extended & momento", disse Lula, 61 anos, em sua \\
discussion with an American journalist & primeira discussão prolongada com um \\
since 2004. & jornalista americano desde 2004.
\end{tabular}

Finalmente, a sétima e última palavra pesquisada foi conversa no CP. Das 975 ocorrências poucas formam uma prosódia positiva junto a conversa: boa (26), verdadeira (5), agradável (5). Com a ocorrência frequente de colocados como mole (30), (para) boi dormir (15), fiada (40), afiada (9), (de) botequim (8) tem-se majoritariamente uma prosódia negativa. A TAB. 9 sinaliza a porcentagem de cada prosódia e mostra que a prosódia negativa é a tendência mais evidente nos colocados aqui apresentados:

\section{TABELA 9}

Tipos de prosódia e suas frequências para conversa

\begin{tabular}{l|c|c}
\hline Prosódia & $\begin{array}{c}\text { Total de ocorrências } \\
\text { dos colocados estudados }\end{array}$ & Frequência em \% \\
\hline Negativa & 102 & $74 \%$ \\
Positiva & 36 & $26 \%$ \\
TOTAL & 138 & \\
\hline
\end{tabular}

Há a tradução de conversation como conversa no corpus paralelo de estudo Brasilis, como na seguinte concordância paralela:

\begin{tabular}{|l|l|}
$\begin{array}{l}\text { A Brazilian military inspector standing } \\
\text { by surprised me by his willingness to talk, } \\
\text { although the conversation was limited } \\
\text { by his weak English and my nonexistent } \\
\text { Portuguese. }\end{array}$ & $\begin{array}{l}\text { Um inspetor militar brasileiro ao lado } \\
\text { me surpreendeu com sua disposição } \\
\text { de conversar, apesar das limitaçôes da } \\
\text { conversa, devido ao seu fraco inglês e } \\
\text { meu português inexistente. }\end{array}$ \\
\hline
\end{tabular}

Nesse exemplo, extraído de um texto sobre um acidente aéreo no Brasil, conversa coloca-se com limitaçôes e fraco confirmando sua tendência a se associar a algo negativo. Chamou-nos a atenção, porém, o fato de to talk ter sido traduzido por conversar, a forma verbal da palavra anterior conversa. Busquei, então, no The Corpus of Contemporary American English (DAVIES, 2008), doravante COCA, o verbo to talk para verificar sua prosódia. Entre os cem primeiros colocados das quase quarenta mil ocorrências extraídas do sítio verificamos a presença de itens que predominantemente atribuem uma prosódia negativa a esse verbo: unable (70), refuse (56), reluctance (22), 
embarrassed (31), forbidden (20), unwilling (18), hesitant (15), ashamed (13). loath (10). Poucos são os que formam uma prosódia positiva: loves (70), honestly (34), pleasure (97), liked (105).

Para conversar, nas 477 ocorrências pesquisadas no CP, apenas um colocado apontou para o padrão de prosódia positiva: amigos (13). Outro colocado forma um padrão de prosódia semântica negativa: tristeza (5). Dentre os colocados mais frequentes estão os verbos vamos (18) e podemos (17) e substantivos que formam a associação com o grupo dos participantes (gente (28), casa (12), padre (10) e aluno (8)). Portanto, a prosódia em português para o verbo conversar é tipicamente neutra enquanto para o substantivo conversa, conforme TAB. 9, é negativa. Assim, pode-se concluir que palavras de mesma raiz não apresentam necessariamente a mesma prosódia (substantivo conversa: negativa; verbo conversar: neutra). A tradução do verbo to talk (prosódia negativa no COCA), traduzido no corpus Brasilis por conversar (prosódia neutra) poderia ser revista para manter-se a prosódia da LF. Sem dúvida, havendo essa informação nos dicionários, pode-se fazer uma escolha mais precisa.

\section{Discussão: as semelhanças e diferenças entre as prosódias nas línguas}

Retomando os itens apresentados na TAB. 2, apresentamos na TAB. 10 a seguir os resultados das comparações das prosódias semânticas nas duas línguas:

\section{TABELA 10}

Itens pesquisados em inglês no Bank of English, as prosódias em inglês, as traduçôes encontradas em português no corpus paralelo de estudo e as prosódias em português $(\mathrm{CP})$

\begin{tabular}{|c|c|c|c|c|}
\hline $\begin{array}{l}\text { Item lexical em } \\
\text { inglês (Bank of } \\
\text { English) }\end{array}$ & $\begin{array}{c}\text { Prosódia semântica } \\
\text { em inglês } \\
\text { (COTERRIL, 2001) }\end{array}$ & $\begin{array}{c}\text { Tradução do item } \\
\text { em português no } \\
\text { corpus paralelo } \\
\text { de estudo }\end{array}$ & $\begin{array}{c}\text { Prosódia } \\
\text { semântica em } \\
\text { português } \\
-(\mathrm{CP})\end{array}$ & $\begin{array}{l}\text { Comparação } \\
\text { entre prosódias } \\
\text { em inglês e } \\
\text { português }\end{array}$ \\
\hline 1. encounter & negativa & encontrar & negativa & igual \\
\hline 2. control & negativa & controlar & neutra & diferente \\
\hline 3. cycle of & negativa & ciclo $\mathrm{de}(\mathrm{o} / \mathrm{a})$ & neutra & diferente \\
\hline 4. incident(s) & neutra, negativa & incidente & negativa & igual \\
\hline 5. dispute & negativa & disputa & neutra & diferente \\
\hline 6. discussion & positiva & discussão & neutra & diferente \\
\hline 7. conversation & positiva & conversa & negativa & diferente \\
\hline
\end{tabular}


Dos sete itens pesquisados, é possível constatar as diferentes prosódias semânticas em cinco itens. Apesar da escolha de palavras cognatas não ter sido objeto desta pesquisa, fica evidente que foi essa a escolha feita na LA. Os tradutores, de maneira consciente ou não, optaram pelos cognatos e cinco deles não expressam as mesmas prosódias da LF. Essas escolhas na LA modificam as prosódias encontradas na LF e não permite que se alcance o sentido pretendido na LF. Por exemplo, no item 5 da TAB. 10, dispute, cuja prosódia semântica é negativa de acordo com o estudo de Coterril, sofre uma alteração de sentido ao ser traduzido para disputa (prosódia semântica neutra) para o português.

Chama a atenção o fato de que quatro das cinco diferenças encontradas deram-se pela neutralidade na língua portuguesa. Em alguns casos, o agrupamento em associações semânticas da prosódia neutra forneceu um perfil que atesta a associação com campos definidos como no caso de ciclo de + evento I substantivos relacionados a ciências. Como salienta Hoey (2005) por vezes a nomenclatura da prosódia semântica limita os achados numa pesquisa sobre os padróes lexicogramaticais e, de acordo com sua proposta, deve-se considerar de maneira mais ampla os grupos semânticos específicos que coocorrem junto a um item lexical. A isso, Hoey denomina de associação semântica em sua obra sobre a teoria do Priming Lexical. Portanto, segundo esse autor, pode-se dizer que ciclo mantém uma associação semântica com itens relacionados a eventos e a ciências, além do caráter neutro da prosódia. Apesar de não ser o objetivo deste trabalho a análise à luz do Priming Lexical, fica clara a necessidade de, em pesquisas futuras, estudarmos as associaçôes semânticas de forma a ampliar a análise indicada pela prosódia semântica que gravita entre positiva, negativa ou neutra.

No caso dos instrumentos de tradução, como os dicionários, seria de grande valia encontrar-se informações como:

cycle of (prosódia negativa); ciclo de (prosódia neutra e associação com eventos e ciência).

Como mencionamos na introdução deste trabalho, a incorporação do uso de corpora e de ferramentas que processem e ilustrem dados da língua em uso por parte de tradutores podem contribuir para o acesso não apenas ao significado das palavras como também a aspectos que indiquem o sentido que certas palavras carregam quando estão nas cercanias de outras.

A descrição da prosódia semântica na língua portuguesa é um campo ainda a ser investigado. Além disso, acreditamos que estudos sistemáticos comparativos entre duas línguas provavelmente permitiriam a obtenção de dados sobre as características semânticas de determinados padrões lexicogramaticais que 
forneceriam subsídios aos instrumentos e obras de referência tradicionalmente usados na prática de tradução.

\section{Conclusão}

Dos estudos citados, apenas os de Partington (1998) e os de Berber Sardinha (1999; 2004) comparam duas línguas para descrever se há uma proximidade ou não entre as prosódias de línguas distintas. $\mathrm{O}$ primeiro, com exemplos em italiano e inglês; e o segundo, inglês e português. Os achados concentram-se nos aspectos positivo ou negativo. Em comum com esta pesquisa está o fato de que ambos os pesquisadores partiram de dados anteriormente pesquisados numa língua para, então, partir para a análise comparativa com outra. A constatação de sentidos neutros que apresentamos com os dados pesquisados nesta pesquisa, porém, é um aspecto que a difere das anteriores.

Parece-nos que, ao se comparar duas línguas, os padrōes lexicogramaticais e suas prosódias, associações ou perfis semânticos, é possível compreender qual o impacto que determinadas combinações provocam. No caso da prática de tradução, essa informação é vital para que a escolha não cause ruídos na comunicação. Exceto se, como aponta Louw (1993), a estranheza for deliberada. Por exemplo, por um lado o leitor da LF de um dos textos do corpus Brasilis, "Brazil tries to ease Bolivian gas dispute", poderá associar o sentido de dispute a algo desfavorável, enquanto o leitor da tradução "Presidente do Brasil se oferece para negociar em tentativa de abrandar disputa sobre o gás boliviano" possivelmente fará uma relação de disputa com um sentido neutro que é a prosódia típica encontrada na língua, conforme analisamos anteriormente. Uma opção seria a escolha por um item para dispute em português cuja prosódia semântica fosse negativa. Tanto a informação na LF como na LA num dicionário bilíngue daria ao tradutor a possibilidade de selecionar um significado que imprimisse um sentido semelhante do texto original.

A ausência de recursos que tratem da prosódia (nódulo + colocado = tipo de prosódia semântica) configura-se como uma dificuldade para o tradutor para manter o sentido da LF na LA. Em especial, no caso dos textos jornalísticos traduzidos para o português do corpus paralelo Brasilis, veiculados pelo seviço de um sítio brasileiro que têm entre seus objetivos tornar possível que "internautas conheçam a visão estrangeira sobre as questôes nacionais". Uma alternativa seria a implementação de um corpus com nódulos e colocados etiquetados com +, -, $\mathrm{n}$ (prosódia positiva, negativa ou neutra) em pelo menos duas línguas como o 
português e o inglês. Outra ideia, mais prática e dinâmica, teria como foco a inserção do uso e o estudo de corpora em cursos de tradução, para que os profissionais da área percebam as vantagens desse recurso e de outros relacionados às ferramentas desenvolvidas por linguistas (em especial de corpus), mas pouco aproveitados nas tradicionais ferramentas de tradução (dicionários e glossários).

Para finalizar, cabe ressaltar que o desenvolvimento e a disponibilização de corpora com informações como as características semânticas (prosódia e associação) podem ir ao encontro das necessidades de tradutores, alunos de tradução e pesquisadores, além de outros estudiosos interessados na descrição das línguas em uso.

\section{Referências}

BERBER SARDINHA, T. Padrões lexicais e colocações do português. 9o. InPLA, PUCSP, Brasil. 1999.

BERBER SARDINHA, T. Linguistica de Corpus. São Paulo: Editora Manole. 2004. BERBER SARDINHA, T. Pesquisa em Linguistica de Corpus com WordSmith Tools. Mercado de Letras: Campinas. 2009.

COTERRIL, J. Domestic discord, rocky relationships: semantic prosodies in representations of marital violence in the O.J. Simpson trial. Discourse \& Society, London: SAGE Publications; v. 12, n. 3, p. 291-312, 2001.

DAVIES, M.; FERREIRA, M. Corpus do Português: 45 milhões de palavras, 1300-1900. Disponível em: < http://www.corpusdoportugues.org/>. Acesso em: 15 jul. 2008.

FIRTH, J.R. Papers in linguistics. London: Oxford University Press, 1957

Lexical Priming: a new theory of words and language. New York: Routeldge, 2005.

HOEY, M. Lexical Priming: a new theory of words and language. New York: Routeldge. 2005

HUNSTON, S.; FRANCIS, G. Pattern Grammar: a corpus-driven approach to the lexical grammar of English. Amsterdam e Philadelphia: John Benjamins, 2000.

KENNY, D. Lexis and Creativity in Translation. Manchester: St. Jerome. 2001.

LOUW, B. Irony in the text or insincerity in the writer: the diagnostic potential of semantic prosodies. In: BAKER, M.; FRANCIS, G.; TOGNINI-BONELLI, E. (Ed.). Text and technology - Essays in honor of John $\mathrm{McH}$ Sinclair. Amsterdam/Atlanta: John Benjamins. 1993. p.157-176.

PARTINGTON, A. Patterns and Meanings - Using Corpora for English Language Research and Teaching. Amsterdam/Philadelphia: John Benjamins. 1998. 
SINCLAIR, J. Mch. Corpus, Concordance, Collocation. Oxford: Oxford University Press, 1991.

SCOTT, M. WordSmith version 4.0. Oxford: Oxford University Press, 2004.

STUBBS, M. Collocations And Semantic Profiles: On The Cause Of The Trouble With Quantitative Studies Functions of Language. John Benjamins Pub. Co. Functions of Language, v. 2, n.1, 1995. Disponível em: <http:// www.unitrier.de/uni/fb2/anglistik/Projekte/stubbs/cause.htm> Acesso em: 10 Jun. 2006.

UOL Mídia Global. UOL Mídia Global traz em português o melhor do jornalismo internacional, 2001. Disponível em <http://sobre.uol.com.br/ultnot/novidade/ noticias/ ult98u231.jhtm>. Acesso em: 9 jan. 2008.

Recebido em 24/07/2010. Aprovado em 31/01/2011. 